\title{
The use of magnetron arrays for depositing large- area oxide coatings
}

\author{
A. Jankowski, M. McKernan, J. Chesser
}

This article was submitted to International Conference on Metallurgical Coatings and Thin Films, San Diego, CA., April 10-14, 2000

\section{February 23, 2000}

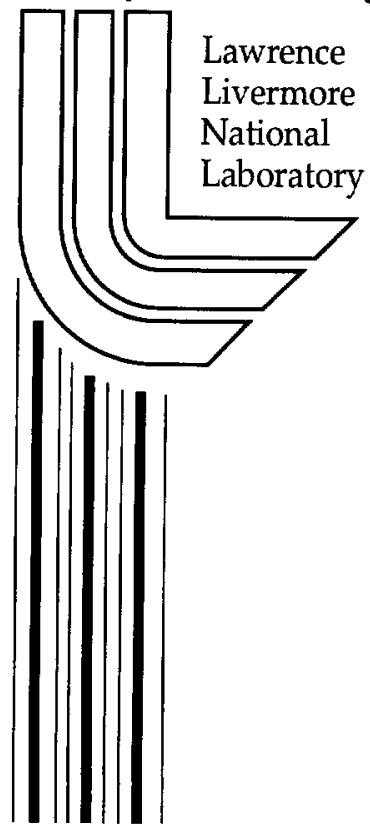




\section{DISCLAIMER}

This document was prepared as an account of work sponsored by an agency of the United States Government. Neither the United States Government nor the University of California nor any of their employees, makes any warranty, express or implied, or assumes any legal liability or responsibility for the accuracy, completeness, or usefulness of any information, apparatus, product, or process disclosed, or represents that its use would not infringe privately owned rights. Reference herein to any specific commercial product, process, or service by trade name, trademark, manufacturer, or otherwise, does not necessarily constitute or imply its endorsement, recommendation, or favoring by the United States Government or the University of California. The views and opinions of authors expressed herein do not necessarily state or reflect those of the United States Government or the University of California, and shall not be used for advertising or product endorsement purposes.

This is a preprint of a paper intended for publication in a journal or proceedings. Since changes may be made before publication, this preprint is made available with the understanding that it will not be cited or reproduced without the permission of the author.

This work was performed under the auspices of the United States Department of Energy by the University of California, Lawrence Livermore National Laboratory under contract No. W-7405-Eng-48.

This report has been reproduced directly from the best available copy.

Available electronically at http://www.doc.gov/bridge

Available for a processing fee to U.S. Department of Energy

And its contractors in paper from

U.S. Department of Energy

Office of Scientific and Technical Information

P.O. Box 62

Oak Ridge, TN 37831-0062

Telephone: (865) 576-8401

Facsimile: (865) 576-5728

E-mail: reports@adonis.osti.gov

Available for the sale to the public from

U.S. Department of Commerce

National Technical Information Service

5285 Port Royal Road

Springfield, VA 22161

Telephone: (800) 553-6847

Facsimile: (703) 605-6900

E-mail: orders@ntis.fedworld.gov

Online ordering: http://www.ntis.gov/ordering.htm

\section{OR}

Lawrence Livermore National Laboratory

Technical Information Department's Digital Library

http://www.llnl.gov/tid/Library.html 


\title{
The use of magnetron arrays for depositing large-area oxide coatings
}

\author{
A. Jankowski, M. MKernan, and J. Chesser \\ Lawrence Livermore National Laboratory \\ P.O. Box 808, Livermore, CA 94551-9900
}

\section{Abstract}

The application of coatings over large areas can be approached through the use of large deposition sources. A versatile alternative, e.g. to long rectangular magnetrons, are linear arrays of circular planar magnetrons to process coatings over wide path lengths. We investigate the feasibility of using a linear array of $76 \mathrm{~mm}$ diameter magnetron sources operated in the rf mode to deposit oxide target materials across a path in excess of $0.7 \mathrm{~m}$ wide. Specific results are given for the case of a $2 \mu \mathrm{m}$ thick, alumina coating. 


\section{INTRODUCTION}

There are a variety of physical vapor deposition methods with which to process coatings over large surface areas. By large, we refer to substrate areas typically in excess of $0.5 \mathrm{~m}^{2}$. For the coating of stainless steel sheet with submicron thick titanium nitride, we see the use of long cathodes up to $1.6 \mathrm{~m}$ in length. ${ }^{[1]}$ For spooled flexible plastic substrates, we see the use of hollow cathode - activated deposition to apply metal-oxide coatings over large areas. ${ }^{[2]}$ For the deposition of field emission cathodes for flat panel displays, we see the use of high rate evaporation coupled with step-and-repeat substrate motion. ${ }^{[3]}$

The use of long, rectangular magnetrons to sputter deposit oxide coatings over large areas is common in a manufacturing environment. The sputter deposition of metal-oxide coatings using rectangular magnetrons operated in the rf mode is a standard process. A wide range of applications for large area, metal-oxide coatings includes the deposition of dielectric layers on silicon, ${ }^{[4]}$ anti-reflective coatings on glass, corrosion resistant coatings on metals, and more recently, multilayers for $\mathrm{x}$-ray optics. An alternative to the rectangular magnetron can be beneficial to minimize the expense of target materials and the cost of large deposition sources.

One feasible approach, demonstrated for the deposition of multilayer coatings on large area, $\mathrm{x}$-ray optics is through the use of an array of circular planar magnetrons. ${ }^{[5]}$ The use of two linear arrays of three, $26 \mathrm{~mm}$ diameter magnetron sources operated in the dc mode provided an effective means to deposit uniformly spaced multilayers across a $15 \mathrm{~cm}$ wide path. A greater number of synchronously operated, larger diameter sources is required for wider coating paths at higher deposition rates. Presently, we investigate the use of a linear array of six, $76 \mathrm{~mm}$ diameter magnetron sources operated in the rf mode to deposit a $2 \mu \mathrm{m}$ thick deposit of alumina across a path in excess of $0.7 \mathrm{~m}$ wide. 


\section{EXPERIMENTS AND RESULTS}

\section{Sample preparation}

The specimens of this study are prepared by planar magnetron, sputter deposition. The vacuum chamber is cryogenically pumped to a base pressure of $6.6 \times 10^{-6} \mathrm{~Pa}$. A linear array of six planar magnetron sources are used with a source-to-source separation of $114 \mathrm{~mm}$. Each planar magnetron has a $76 \mathrm{~mm}$ diameter. The source-to-substrate separation is $83 \mathrm{~mm}$. The target material is alumina $\left(\mathrm{Al}_{2} \mathrm{O}_{3}\right)$ and the substrates are polished $\mathrm{Si}$ wafers covered by a hard mask as a template to create a grid pattern. Each circular opening of the $x-y$ grid is separated by $19 \mathrm{~mm}$ on center, extending over a total area that is $152 \mathrm{~mm}$ in width by $0.8 \mathrm{~m}$ in height. The substrate table is held at room temperature. The magnetron sources ( 1 through 6 ) are operated in the if mode. The Ar working gas pressure $\left(\mathrm{p}_{\mathrm{Ar}}\right)$ and gas flow $\left(\mathrm{q}_{\mathrm{Ar}}\right)$ is generated from the boil-off of liquid argon. For each deposition experiment, 600 Watts total of forward power $\left(\mathrm{P}_{\mathrm{for}}\right)$ is delivered from one rf generator for a specific interval of time $(\mathrm{t})$. Three network splitters are used to divide the power amongst pairs (A, B and C) of the magnetron sources. The thickness profiles of the sputter deposited coatings, generated using the magnetron source arrays for the sputter process parameters listed in Table 1, are measured from the masked 6D Si wafers using contact profilometry. The power distribution form the paired magnetron sources are listed in Table 2 along with the percentage of reflected power $\left(\mathrm{P}_{\text {refl }}\right)$. These process parameters minimize the effects of energetic sputtered neutrals, that is ballistic adatom bombardment at the substrate. ${ }^{[6]}$ The deposition rates from each source are 0.48 to $0.85 \mathrm{~nm}$ (W $\mathrm{hr})^{-1}$ under these deposition conditions. 


\section{Structural characterization}

Scanning electron microscopy of cross-sectioned alumina samples reveal the growth morphology. A dense microstructure is evident throughout the cross-section as imaged with secondary and backscattered electrons for all samples. A typical example is seen in the fracture cross-section (Fig. 1) of a $1 \mu \mathrm{m}$ thick region taken from the perimeter of coating no. 4 . The fracture mode appears smooth without the presence of distinct columnar features as is typical of brittle fracture in a glassy material.

$\mathrm{X}$-ray diffraction is used for phase identification of the sputtered deposit. Analysis of $\mathrm{Cu} K \alpha$ diffraction scans in the $\theta / 2 \theta$ mode taken at high $\left(30^{\circ}-80^{\circ}\right)$ indicates the lattice spacings of the coating and substrate. A long $(4 \mathrm{sec})$ count time coupled with a fine $\left(0.02^{\circ}\right) 2 \theta$ increment is used to provide a reflected signal from the apparently glassy coating (of Fig. 1). This beam conditions yields an intense (greater than $250 \times 10^{3} \mathrm{cts} \mathrm{s}^{-1}$ ) peak for the Si (400) substrate evidenced by a doublet reflection at $2 \theta$ positions of $69.1^{\circ}$ and $69.3^{\circ}$, indicative of the $\mathrm{Cu} K \alpha_{1}$ and $\mathrm{Cu} \mathrm{K} \alpha_{2}$, split in the incident $\mathrm{x}$-ray beam. This result is typical for scattering from the $1-2^{\circ}$ misorientation found for highly polished Si wafers. In addition to the diffuse Si (200) reflection found above the $2 \theta$ position of $33^{\circ}$, diffuse reflections are found (Fig. 2 ) at the $2 \theta$ positions of $35^{\circ}$ and $45^{\circ}$ for the sample from the perimeter region of the alumina coating no. 4 . These broad $\left(2^{\circ}-3^{\circ}\right)$, full-width-half-maximums would indicate a glassy or nanocrystalline deposit. The best fit for this spectra is the corrundum phase of alumina having primary (104) and (113) reflections at $2 \theta$ positions of $35.1^{\circ}$ and $43.4^{\circ}$, respectively. 


\section{Profilometry}

The thickness of the alumina coatings are measured using contact profilometry. The contour plots (Figs. 3-5) of the three alumina coating experiments all evidence a peak-to-valley topology consistent with the position of each magnetron source. For coatings no. 2 and 3 , the magnetron sources are paired identically (Table 2 ) producing similar profile results although processed at two different gas pressures (Table 1). The decrease in peak thickness (Figs. 3 and 4) correlates with the progressive decrease in forward power and increase in reflected power as the magnetron array progresses in pairs from sources no. 1 to 6 . The higher working gas pressure used for coating no. 3 (Fig. 4) as opposed to coating no. 2 (Fig. 3) produces a lower deposition rate as is consistent with the increased scattering of the sputtered neutrals, yet the thickness uniformity is unimproved. The change in magnetron pairing directly influences the thickness profile. The three network splitters $(\mathrm{A}, \mathrm{B}$, and $\mathrm{C})$ do influence the power distribution to the magnetrons and it is unequal. The change in magnetron pairing directly correlates with changes measured in the forward/reflected power from each magnetron source. The thickness maxima observed for (A) paired sources no. 1 and 2 in coatings no. 2 and 3, shifts to sources no. 1 and 4 in coating no. 4 as these sources are now (A) paired.

\section{Discussion AND SUMmARY}

The use of a linear array of planar magnetrons can be used to produce a metal-oxide coating over a path in excess of $0.7 \mathrm{~m}$ wide. We have demonstrated that six planar magnetrons can be operated in the if mode using just one single rf generator. This is a cost effective alternative to the use of single source generators and matching networks. The distribution of power to the magnetron sources is accomplished in pairs using network splitters. Without an 
attempt to balance the forward power output, variations in thickness will correspondingly occur. A peak-to-valley thickness variation will be commensurate with the spacing between magnetron sources. The quality of the alumina coating as viewed by morphology and phase is comparable to those produced using large rectangular magnetrons. If the uniformity in coating thickness across the array can be improved, then this approach offers a viable cost (of targets, power supply, and source) effective alternative to large rectangular magnetrons.

\section{ACKNOWLEDGMENT}

This work was performed under the auspices of the U.S. Department of Energy by University of California, Lawrence Livermore National Laboratory under contract No. W-7405-Eng-48. 


\section{References}

1 D. Hofmann and S. Shiotani, Surf. Coat. Technol., 54-5 (1992) 586

2 H. Morgner, M. Neumann, S. Straach, and M. Krug, Surf. Coat. Technol., 108-9 (1998) 513

3 A. Jankowski, J. Hayes, J. Morse, and J. Ferreira, Thin Solid Films, 355-6 (1999) 194

4 A.F. Jankowski, Thin Solid Films, 332 (1998) 272

5 A.F. Jankowski, D.M. Makowiecki, R.J. Foreman, M.A. MKernan and R.G. Patterson, in X-Ray/EUV Optics for Astronomy, Microscopy. Polarimetry. and Projection Lithography, Int'l. Soc. Opt. Eng'g. Proc. Vol. 1343, SPIE - Int'l. Soc. Opt. Eng'g., Bellingham, 1990, p. 32

6 J.A. Thornton, Ann. Rev. Mater. Sci., 7 (1977) 239 
Table 1. Sputter Process Parameters

Coating (no.) $\quad \mathrm{p}_{\mathrm{Ar}}(\mathrm{Pa}) \quad \mathrm{q}_{\mathrm{Ar}}\left(\mathrm{cm}^{3} \mathrm{~m}^{-1}\right) \quad \mathrm{P}_{\text {for }} \mathrm{t}(\mathrm{kW} \mathrm{hr})$

$\begin{array}{llll}2 & 2.0 & 33 & 3.2 \\ 3 & 4.0 & 33 & 4.0 \\ 4 & 2.0 & 62 & 3.2\end{array}$


Table 2. Sputter Power Distribution

\begin{tabular}{ccccccc} 
Magnetron & \multicolumn{3}{c}{ Coating no. 2} & \multicolumn{3}{c}{ Coating no. 4} \\
Source (no.) & Pair & $\mathrm{P}_{\text {for }}(\%) \mathrm{P}_{\text {refl }} / \mathrm{P}_{\text {for }}(\%)$ & Pair & $\mathrm{P}_{\text {for }}(\%) \mathrm{P}_{\text {reff }} / \mathrm{P}_{\text {for }}(\%)$ \\
1 & A & 100 & 5.6 & A & 100 & 6.9 \\
2 & A & 102 & 4.8 & C & 98 & 5.8 \\
3 & B & 98 & 8.7 & B & 90 & 12.7 \\
4 & B & 103 & 5.0 & A & 105 & 6.6 \\
5 & C & 93 & 9.1 & C & 97 & 8.5 \\
6 & C & 91 & 17.8 & B & 91 & 17.3
\end{tabular}




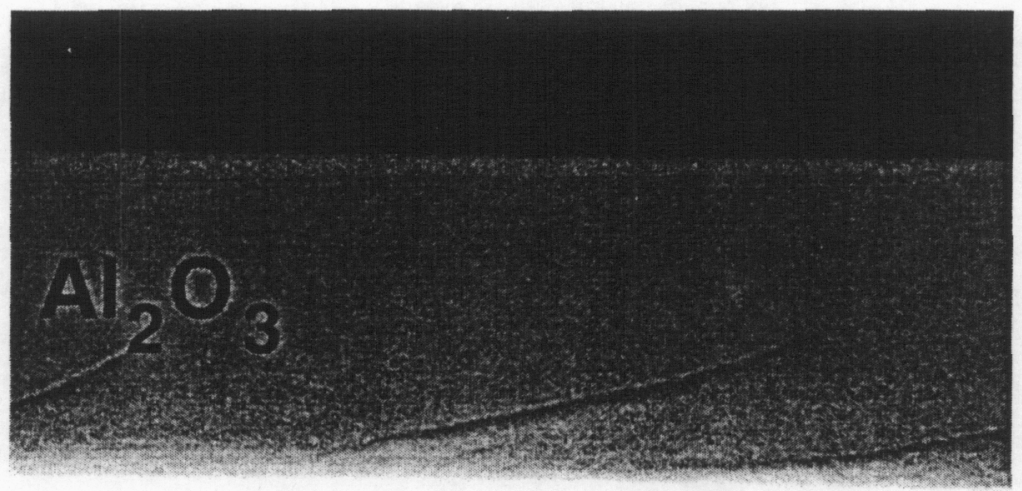

\section{Si}

\section{1. $6 \mathrm{kV} \times 30.0 \mathrm{k}$ i:}

Fig. 1 A scanning electron micrograph of a cross-sectioned region a $1 \mu \mathrm{m}$ thick region taken from the perimeter of the alumina coating no. 4 . 


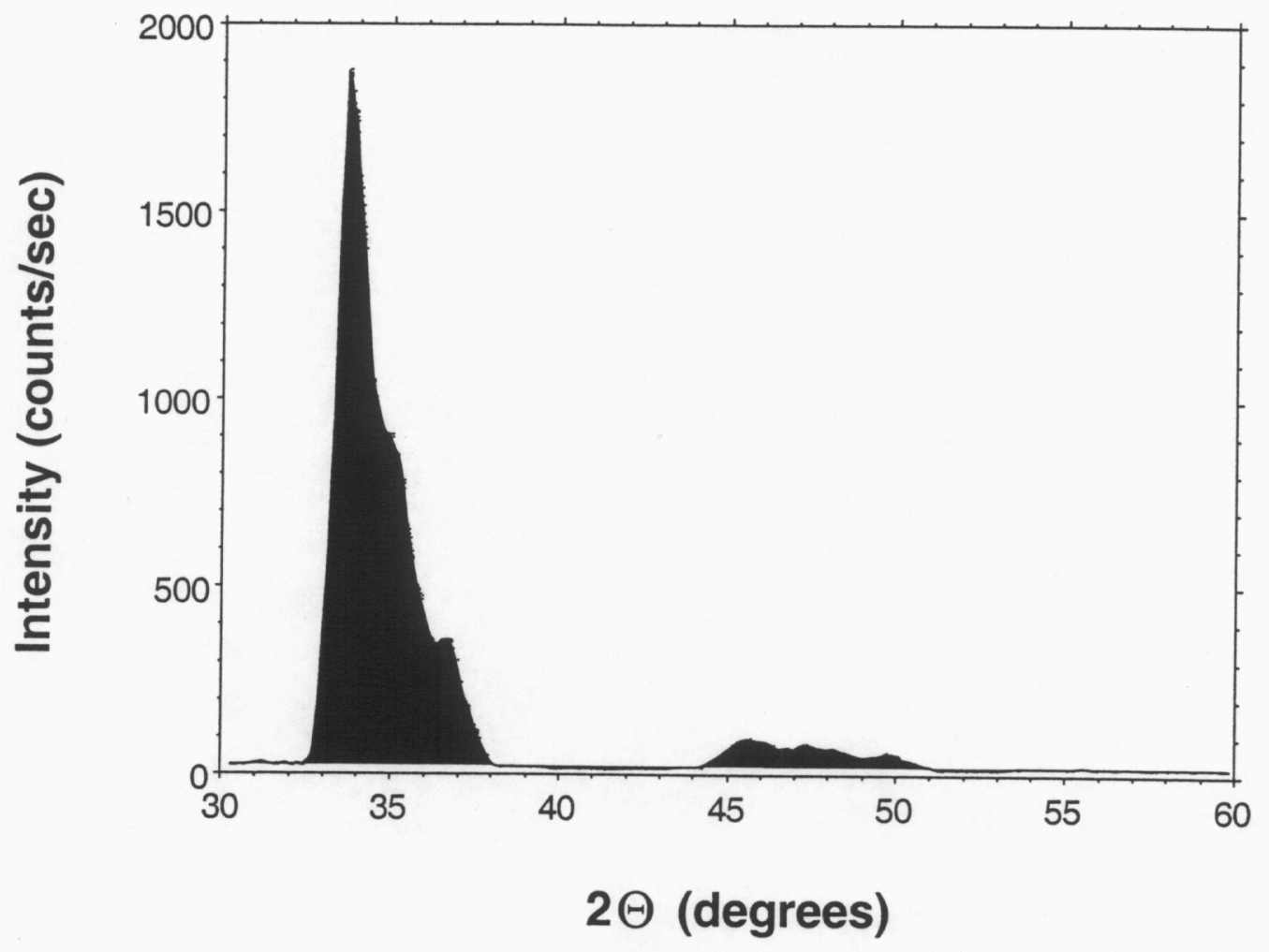

Fig. $2 \mathrm{Cu} K \alpha$ diffraction scans taken in the $\theta / 2 \theta$ mode as sampled from the perimeter of alumina coating no. 4 . 


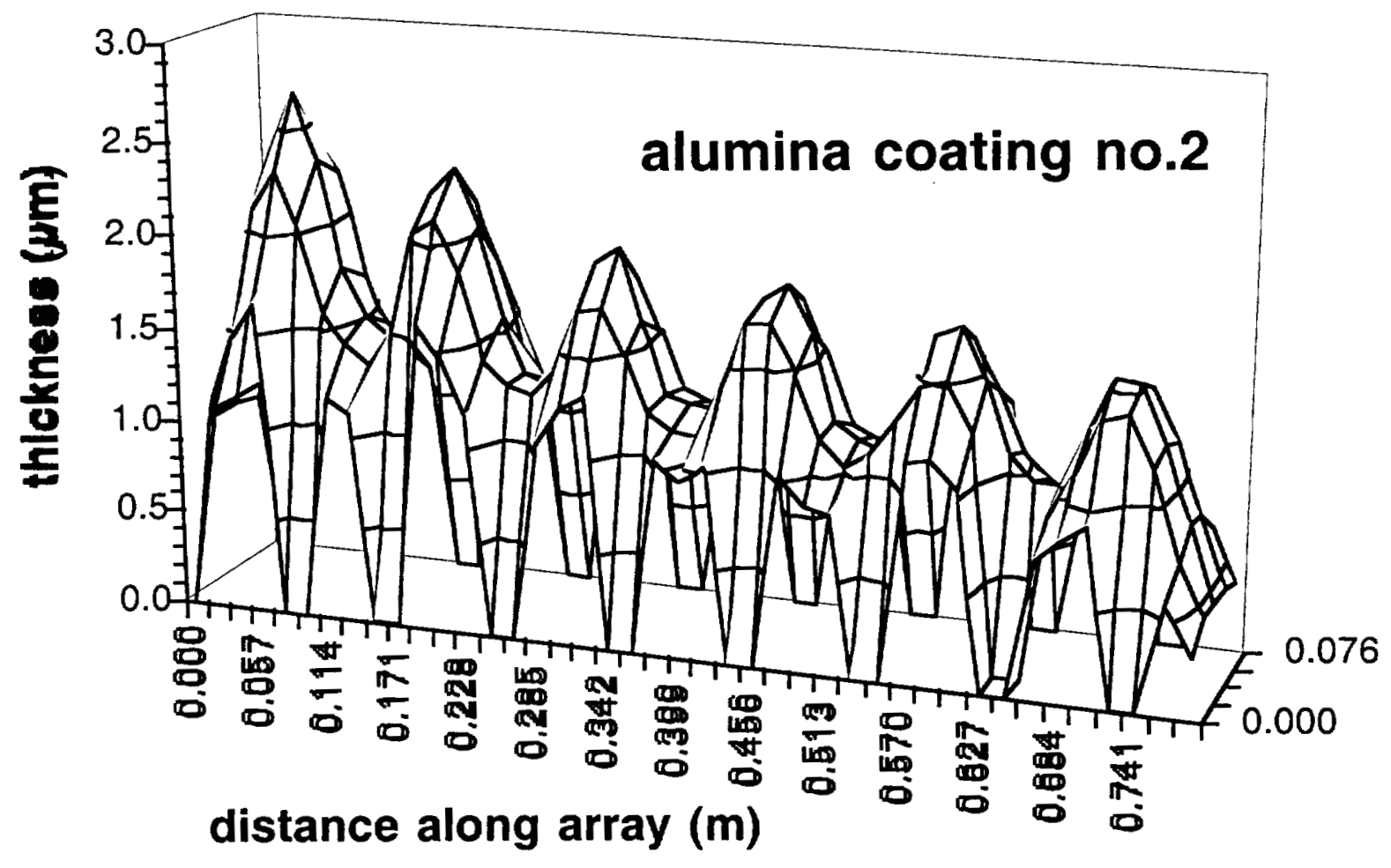

Fig. 3 The thickness contour plot for the six source magnetron array of coating no. 2 . 


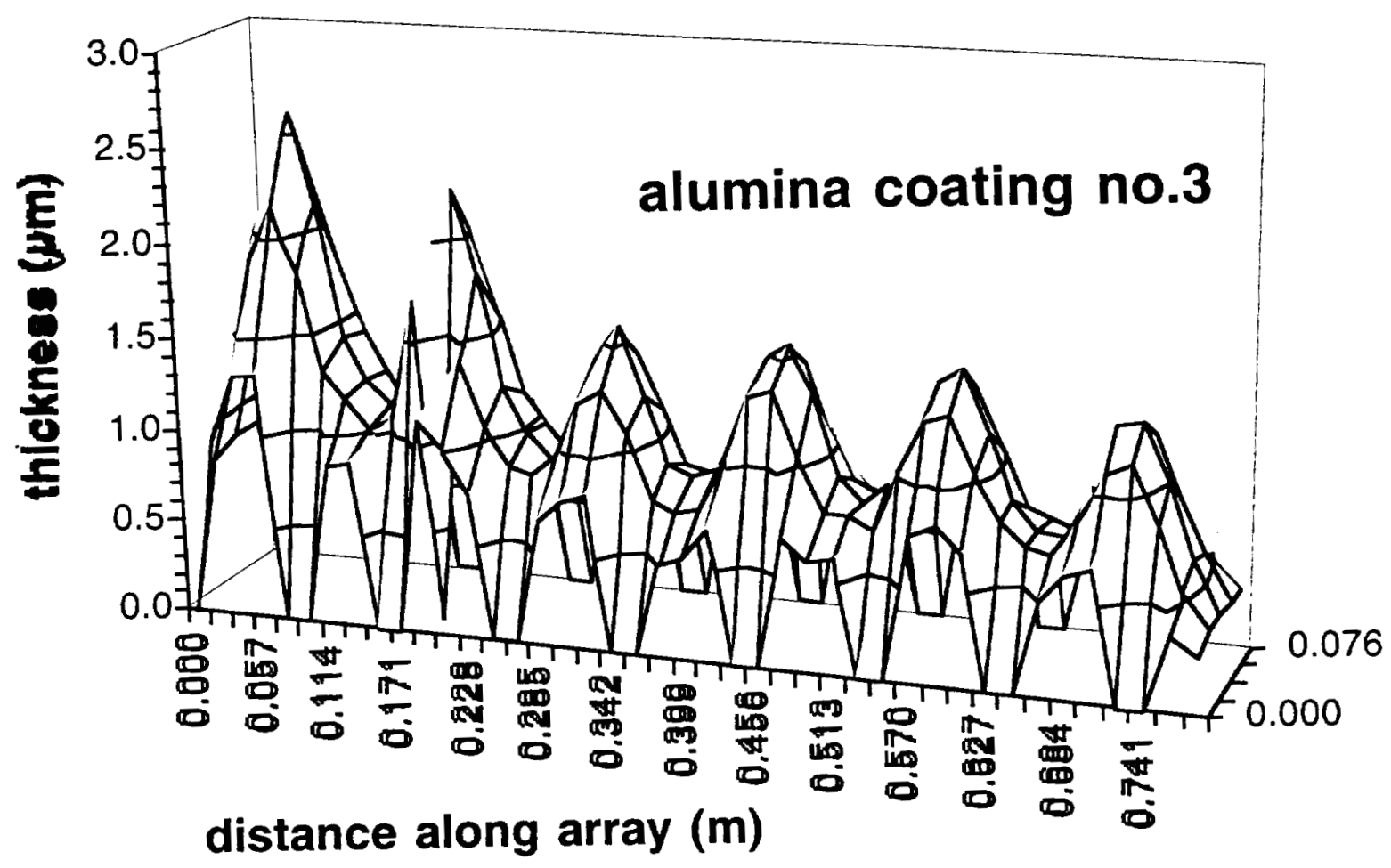

Fig. 4 The thickness contour plot for the six source magnetron array of coating no. 3. 


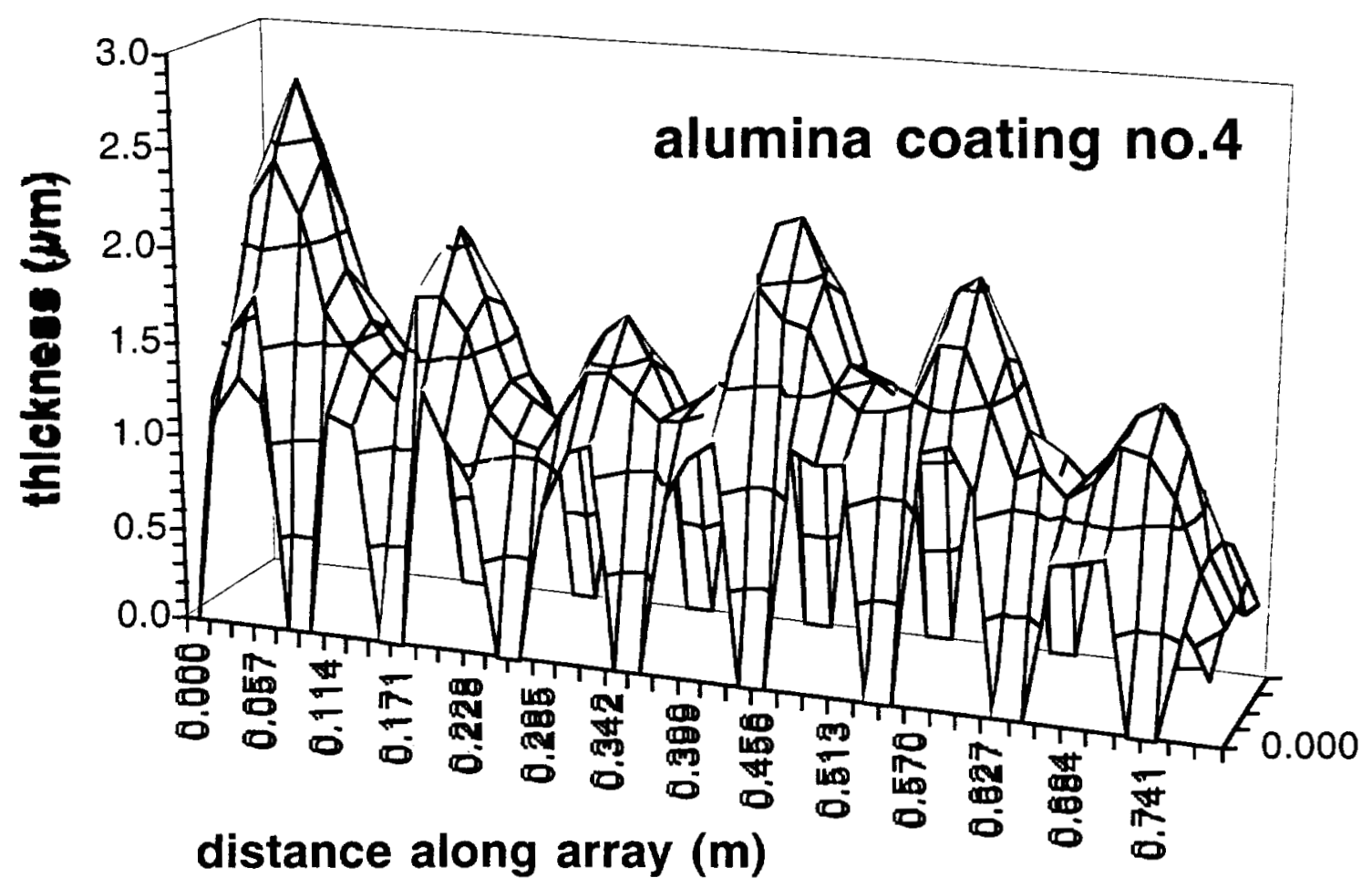

Fig. 5 The thickness contour plot for the six source magnetron array of coating no. 4 . 